\title{
CAMINO HACIA LA WEB SEMÁNTICA
}

Jorge Alejandro Castillo Morales

\section{RESUMEN}

El rápido crecimiento de la Word Wide Web ocasiona que sea cada vez más difícil buscar, extraer, interpretar y procesar información de la Web. Como una alternativa a este problema se está desarrollando la Web Semántica una nueva tecnología que hace que el contenido de la Web sea más significativo a las aplicaciones de software. En la Web Semántica se aumentan anotaciones que expresan el significado de los datos en las páginas Web. Para que estas anotaciones sean útiles, es necesario un entendimiento compartido (entre sus creadores y los usuarios) de anotaciones precisamente definidas. Con este propósito se utilizan ontologías - definición de conceptos importantes en un dominio de conocimiento y de las propiedades de cada concepto. Las ontologías permiten definir terminologías y expresar propiedades semánticas. Como resultado, la Web Semántica promete proveer un nivel de automatización e integración que es imposible para la Web actual. Asimismo, la Web Semántica va a poder ejecutar consultas avanzadas que requieren conocimiento de soporte para su resolución.

Palabras Clave: World Wide Web, Web Semántica, Ontologías. 